\title{
Intrathecal levobupivacaine versus bupivacaine for inguinal hernia surgery: a randomized controlled trial
}

\author{
Ajay Singh ${ }^{1}$, Anshu Gupta ${ }^{2}$, Priyankar Kumar Datta ${ }^{1}$, and Maitree Pandey ${ }^{2}$ \\ ${ }^{1}$ Department of Anesthesiology, Pain Medicine and Critical Care, All India Institute of Medical Sciences, \\ ${ }^{2}$ Department of Anesthesiology and Critical Care, Lady Hardinge Medical College, New Delhi, India
}

Background: Levobupivacaine is an attractive alternative to racemic bupivacaine for spinal anesthesia due to the lower potential for cardio-toxicity and faster recovery profile. This study was designed to compare isobaric levobupivacaine with hyperbaric racemic bupivacaine with respect to intraoperative quality of anesthesia and the postoperative recovery profile in patients undergoing inguinal hernia surgery.

Methods: A total of 100 American Society of Anesthesiologists 1 and 2 patients, aged 18-60 years, undergoing elective daycare unilateral inguinal hernia surgery, were randomized into two groups. Group L received spinal anesthesia with 3 $\mathrm{ml}$ of $0.5 \%$ plain levobupivacaine. Group B received $3 \mathrm{ml}$ of $0.5 \%$ hyperbaric racemic bupivacaine. Quality of anesthesia, sensory and motor block characteristics, duration of effective analgesia, time to mobilization, and incidence of side effects were compared.

Results: The quality of anesthesia was comparable between the two groups. No difference was observed in the block onset time or maximum block height. The duration of anesthesia was significantly shorter in group L compared with that in group B $(206.2 \pm 18.9 \mathrm{~min}$ vs. $224.1 \pm 15.6 \mathrm{~min}, \mathrm{P}<0.001)$, as was duration of motor block $(185.9 \pm 20.3 \mathrm{~min}$ vs. $196.4 \pm$ $21.2 \mathrm{~min}, \mathrm{P}=0.016)$ and time to walk unaided $(321.9 \pm 19.2 \mathrm{~min}$ vs. $356.7 \pm 26.6 \mathrm{~min}, \mathrm{P}<0.001)$. The incidence of hypotension was less in group $\mathrm{L}(12 \%)$ compared to group $\mathrm{B}(32 \%)(\mathrm{P}=0.028)$.

Conclusions: Levobupivacaine is an effective alternative to bupivacaine for patients undergoing unilateral inguinal hernia surgery. It has a shorter duration of sensory and motor block, allowing earlier mobilization in daycare surgeries, and a lower incidence of intraoperative hypotension.

Keywords: Bupivacaine; Levobupivacaine; Spinal anesthesia.

Corresponding author: Ajay Singh, M.D.

Department of Anesthesiology, Pain Medicine and Critical Care, All India Institute of Medical Sciences, New Delhi 110029, India

Tel: +91-99276845, Fax: +91-26593212

Email: ajay.ydv2509@gmail.com

ORCID: https://orcid.org/0000-0003-1526-5370

Received: August 8, 2017.

Revised: September 8, 2017 (1st); September 22, 2017 (2nd).

Accepted: October 1, 2017.

Korean J Anesthesiol 2018 June 71(3): 220-225

https://doi.org/10.4097/kja.d.18.27191

\section{Introduction}

Spinal anesthesia has been a popular anesthesia technique for short, lower abdominal and inguinal hernia surgeries. Hyperbaric racemic bupivacaine is commonly used for spinal anesthesia due to its long duration of action and combined motor and sensory blockade. However, the use of hyperbaric racemic bupivacaine in spinal anesthesia has some drawbacks. It has a high propensity to cause hypotension and bradycardia following intrathecal injection, and there is potential for catastrophic cardiac toxicity due to the high affinity of bupivacaine to cardiac

(c) This is an open-access article distributed under the terms of the Creative Commons Attribution Non-Commercial License (http://creativecommons.org/ licenses/by-nc/4.0/), which permits unrestricted non-commercial use, distribution, and reproduction in any medium, provided the original work is properly cited. 
myocytes $[1,2]$.

Racemic bupivacaine is an equimolar mixture of dextro and levobupivacaine. Levobupivacaine has a lower affinity for cardiac sodium channels and greater plasma protein binding affinity compared with the dextro isomer; thus, reducing the risk of cardio-toxicity [3-5]. Plain levobupivacaine has been shown to be isobaric with respect to cerebrospinal fluid [6] and thus leads to more predictable drug spread, decreasing the incidence of hypotension and bradycardia $[7,8]$. Levobupivacaine also results in earlier motor recovery compared with racemic bupivacaine $[8,9]$. These advantages make levobupivacaine an attractive alternative to racemic bupivacaine for spinal anesthesia.

This study was designed to compare isobaric levobupivacaine with hyperbaric racemic bupivacaine with respect to intraoperative quality of anesthesia and the postoperative recovery profile in patients undergoing inguinal hernia daycare surgery.

\section{Materials and Methods}

Our hypothesis was that isobaric levobupivacaine offers equivalent intraoperative quality of anesthesia and a better postoperative recovery profile compared with hyperbaric racemic bupivacaine. This study was designed as a doubleblinded randomized control trial. Institutional ethics committee approval was obtained before patient enrollment, and the study was registered in the National Clinical Trial Registry (CTRI/2016/10/007342). In total, 100 American Society of Anesthesiologists 1 and 2 patients, aged 18-60 years, who were undergoing elective daycare unilateral inguinal hernia surgery, were randomized into two groups based on a computer-generated randomized table using the opaque envelope technique.

- Group L- intrathecal isobaric levobupivacaine.

- Group B- intrathecal hyperbaric racemic bupivacaine.

All patients underwent a preanesthetic evaluation. Patients of height $145-180 \mathrm{~cm}$, weighing $50-100 \mathrm{~kg}$ were included in the study, and patients having uncontrolled systemic illness or any contraindication to spinal anesthesia were excluded from recruitment. Cases with undue prolongation of surgery beyond $2 \mathrm{~h}$ were excluded from analysis.

Patients were admitted on the morning of surgery. They were asked to avoid solid food for $8 \mathrm{~h}$ prior to the scheduled time of surgery, but allowed to take clear liquids up to $2 \mathrm{~h}$ prior to surgery. After shifting the patient to the operating table, electrocardiogram, peripheral capillary oxygen saturation, and noninvasive blood pressure (NIBP) monitors were attached and baseline values of heart rate (HR) and blood pressure (BP) were noted. After securing an 18-G intravenous catheter, patients were preloaded with $10 \mathrm{ml} / \mathrm{kg}$ of Ringer's lactate over $10 \mathrm{~min}$. Before commencement of anesthesia, patients were instructed on the method of sensory and motor assessment. A sub-arachnoid block was performed in the sitting position in the L2/L3 or L3/ L4 intervertebral space using a $25 \mathrm{G}$ Quinke spinal needle. After confirming free flowing cerebrospinal fluid, the study drug was given slowly over $15 \mathrm{~s}$ according to the group allocation.

- Group L ( $\mathrm{n}=50): 3 \mathrm{ml}$ of 0.5\% levobupivacaine (isobaric).

- Group B ( $\mathrm{n}=50): 3 \mathrm{ml}$ of $0.5 \%$ bupivacaine (hyperbaric).

Immediately after the intrathecal injection, patients were placed in the supine position. An anesthesiologist, who was blinded to the local anesthetic used, assessed the sensory and motor block.

An incision was made once the sensory block of at least T8 level was achieved, along with motor block of modified Bromage grade 2 (10) or less. If these were not achieved in $20 \mathrm{~min}$, it was considered failed spinal anesthesia and converted to general anesthesia.

\section{Observation}

After injecting the intrathecal drug, the following parameters were observed by an anesthesiologist who was blinded to the type of drug given to the patient. NIBP and HR were noted every minute for $10 \mathrm{~min}$ and then every $5 \mathrm{~min}$ until the end of surgery. A hypotensive episode was defined as systolic blood pressure $(\mathrm{SBP})<90 \mathrm{mmHg}$ or a decrease in SBP $\geq 20 \%$ of the baseline value. Hypotension was managed by rapid infusion of $250 \mathrm{ml}$ of Ringer's lactate and $3 \mathrm{mg}$ incremental doses of intravenous mephentermine. Clinically relevant bradycardia was defined as a $\mathrm{HR}<50 \mathrm{bpm}$ and was managed with incremental doses of $0.3 \mathrm{mg}$ intravenous atropine.

The onset of sensory block was defined as the time taken for loss of sharp sensation with the pinprick test until the T8 dermatome level after injecting the drug $\left(\mathrm{T}_{\mathrm{T} 8}\right)$. The recordings were noted every minute for the initial $10 \mathrm{~min}$, and then every $5 \mathrm{~min}$ thereafter. The maximum height of sensory block reached was also noted $\left(\mathrm{H}_{\max }\right)$. The time taken for regression of the block to two segments after injecting the drug was noted $\left(\mathrm{T}_{\text {reg2 }}\right)$. Motor blockade was assessed using the modified Bromage scale (modified Bromage scale: 1 = unable to move feet or knees, 2 = able to move feet only, 3 = just able to move knees, 4 = full flexion of knees with detectable weakness of hip flexion while supine, $5=$ no detectable weakness of hip flexion while supine, $6=$ able to perform partial knee bend) [10]. The time taken to achieve adequate motor block $\left(\mathrm{T}_{\mathrm{Brom} 2}\right)$, defined as a score of 2 on the modified Bromage scale, was recorded by testing the motor block every minute until a score of 2 was achieved.

Surgery was commenced once adequate sensory (T8) and motor (modified Bromage 2) block was achieved. The quality of surgical anesthesia was scored as follows depending on the patient's response:

- Excellent (Score 4): No complaint from the patient at any 
time during the surgery.

- Satisfactory (Score 3): Patient allowed the surgery but sometimes complained of uneasiness, requiring supplemental analgesia with intravenous fentanyl $(0.5 \mu \mathrm{g} / \mathrm{kg}$ bolus $)$ - maximum $4 \mu \mathrm{g} / \mathrm{kg}$.

- Inadequate (Score 2): Patient complained of pain and required conversion to general anesthesia.

- Failure (Score 1): Adequate sensory level or motor block not achieved.

After the surgery, the patients were shifted to the post-anesthesia care unit and standard monitoring was continued. The sensory level and motor blockade were checked every $10 \mathrm{~min}$. The duration of anesthesia $\left(\mathrm{T}_{\text {anes }}\right)$ was defined as the time interval between the onset of sensory block (T8 level) to regression of the sensory block to the L1 dermatome. The duration of the motor block $\left(\mathrm{T}_{\mathrm{MB}}\right)$ was defined as the time interval between the onset of motor block (modified Bromage scale 2) to the achievement of modified Bromage scale 6 after the surgery. The time interval between administration of the subarachnoid block and the first request for supplemental analgesia by the patient was noted as the duration of effective analgesia $\left(\mathrm{T}_{\text {analg }}\right)$. Once a modified Bromage score of 6 was achieved, patients were encouraged to stand up and walk initially with support and then unaided.
The time taken to walk confidently without support $\left(\mathrm{T}_{\text {walk }}\right)$ and the time taken for the patient to void urine $\left(\mathrm{T}_{\text {void }}\right)$ were noted.

\section{Outcomes}

The primary outcome was the difference in mean score of intraoperative quality of anesthesia. Secondary outcomes were the time taken to achieve adequate sensory and motor blockade, incidence of hypotension and bradycardia, total duration of sensory and motor blockade, duration of effective analgesia, time taken to walk unaided $\left(\mathrm{T}_{\text {walk }}\right)$, and time to self-void $\left(\mathrm{T}_{\text {void }}\right)$.

\section{Sample size calculation}

Sample size was calculated using the Statstodo open access online calculator. We considered a difference of 0.5 in the mean score for intraoperative quality of anesthesia to be clinically significant. With an expected standard deviation of 0.5 , an acceptable alpha error of $5 \%$, and a power of the study of $99 \%$, we required 32 patients in each group for a one-tailed analysis. Thus, with an added safety margin, we recruited 100 patients in the trial.

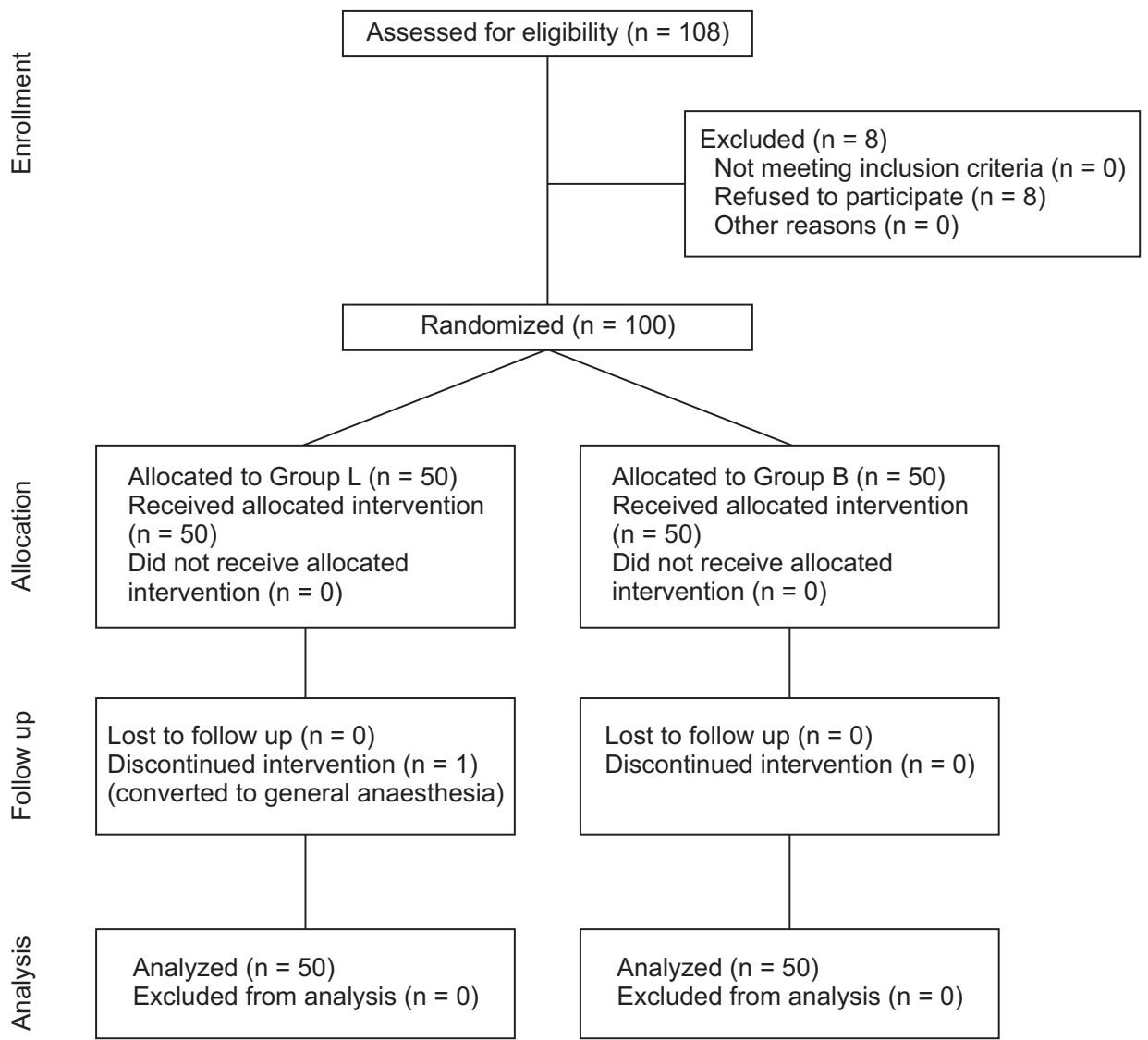

Fig. 1. CONSORT diagram showing the flow of participants through each stage of the trial. 


\section{Statistical methods}

Data were analyzed using IBM SPSS Statistics (IBM Corp., USA) for Windows, Version 20.0. Data are presented as number (\%) or mean \pm SD as appropriate. Quantitative data were compared using one-way analysis of variance. Qualitative variables were compared using Fisher's exact test. A P value $<0.05$ was considered significant.

Table 1. Patients' Characteristics and Duration of Surgery

\begin{tabular}{lccc}
\hline & $\begin{array}{c}\text { Group L } \\
(\mathrm{n}=50)\end{array}$ & $\begin{array}{c}\text { Group B } \\
(\mathrm{n}=50)\end{array}$ & P value* \\
\hline Age $(\mathrm{yr})$ & $35.3 \pm 9.2$ & $35.8 \pm 8.9$ & 0.387 \\
Weight $(\mathrm{kg})$ & $59.3 \pm 7.2$ & $60.2 \pm 7.1$ & 0.251 \\
Height $(\mathrm{cm})$ & $164.3 \pm 5.2$ & $163.2 \pm 6.0$ & 0.169 \\
Duration of surgery (min) & $122.6 \pm 13.1$ & $123.4 \pm 11.9$ & 0.436
\end{tabular}

Values are mean \pm SD. Group L: levobupivacaine, Group B: bupivacaine. *One-way analysis of variance.

Table 2. Quality of Anesthesia

\begin{tabular}{lcc}
\hline & Group L $(\mathrm{n}=50)$ & Group B (n=50) \\
\hline Excellent (score $=3)$ & 44 & 46 \\
Satisfactory (score $=2)$ & 5 & 4 \\
In-adequate (score $=1)$ & 1 & 0 \\
Failure (score $=0)$ & 0 & 0 \\
Net score \pm SD & $2.86 \pm 0.40$ & $2.92 \pm 0.27$ \\
P value* & & 0.387 \\
\hline
\end{tabular}

Values are number of patients or mean \pm SD. Group L: levobupivacaine, Group B: bupivacaine. *One-way analysis of variance.

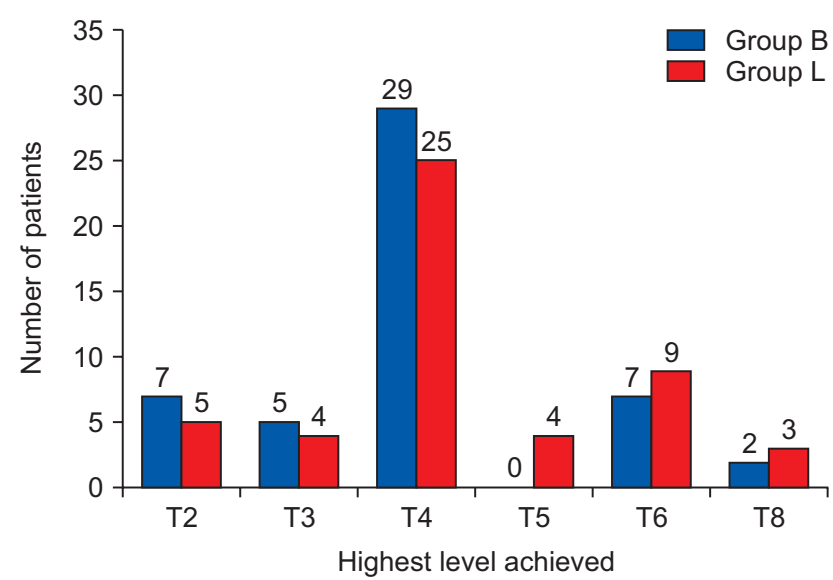

Fig. 2. Highest level of sensory block achieved in the two groups. Values are number of patients. Group L: levobupivacaine, Group B: bupivacaine.

\section{Results}

Fig. 1 shows the flow of patients through each phase of the trial. Both groups were comparable with respect to age, height, weight, and duration of surgery (Table 1). The intraoperative quality of anesthesia was comparable in both groups (Table 2). Fig. 2 shows the highest level of sensory block achieved in the two groups. No significant difference was observed between the two groups. The majority of patients achieved T4 sensory block level in both groups.

Table 3 shows the sensory and motor block characteristics. Duration of anesthesia $\left(\mathrm{T}_{\text {anes }}\right)$ was significantly shorter in group L (206.2 $\pm 18.9 \mathrm{~min})$ compared with group B (224.1 $\pm 15.6 \mathrm{~min})$, as was the duration of motor blockade $\left(\mathrm{T}_{\mathrm{MB}}\right.$ ) (group L $185.9 \pm$ $20.3 \mathrm{~min}$ vs. group B $196.4 \pm 21.2 \mathrm{~min}$ ). Time to ambulation $\left(\mathrm{T}_{\text {walk }}\right)$ was shorter in group $\mathrm{L}(321.9 \pm 19.2 \mathrm{~min})$ compared with group B $(356.7 \pm 26.6 \mathrm{~min})$.

Table 4 shows the incidence of adverse events. The incidence of hypotension was higher with bupivacaine (16 of 50) than with levobupivacaine (6 of 50). No differences in the incidence of bradycardia, nausea, or vomiting were observed.

Table 3. Characteristics of Sensory and Motor Block

\begin{tabular}{lccc}
\hline Time (min) & $\begin{array}{c}\text { Group } \mathrm{L} \\
(\mathrm{n}=50)\end{array}$ & $\begin{array}{c}\text { Group B } \\
(\mathrm{n}=50)\end{array}$ & P value* \\
\hline $\begin{array}{l}\text { Time to sensory block } \\
\text { onset } \mathrm{T}_{\mathrm{T} 8}\end{array}$ & $4.4 \pm 2.1$ & $4.2 \pm 1.7$ & 0.635 \\
$\begin{array}{l}\text { Time to two segment } \\
\text { regression } \mathrm{T}_{\text {reg2 }}\end{array}$ & $133.5 \pm 15.8$ & $137.4 \pm 12.3$ & 0.171 \\
$\begin{array}{l}\text { Duration of anesthesia } \\
\mathrm{T}_{\text {anes }}\end{array}$ & $206.2 \pm 18.9$ & $224.1 \pm 15.6$ & $<0.001$ \\
$\begin{array}{l}\text { Onset of motor block } \\
\mathrm{T}_{\text {Brom2 }}\end{array}$ & $4.3 \pm 1.7$ & $4.1 \pm 1.2$ & 0.496 \\
$\begin{array}{l}\text { Duration of motor block } \\
\mathrm{T}_{\mathrm{MB}}\end{array}$ & $185.9 \pm 20.3$ & $196.4 \pm 21.2$ & 0.016 \\
$\begin{array}{l}\text { Duration of effective } \\
\text { analgesia } \mathrm{T}_{\text {analg }}\end{array}$ & $238.2 \pm 19.1$ & $243.9 \pm 13.8$ & 0.092 \\
$\begin{array}{l}\text { Time to void urine } \mathrm{T}_{\text {void }} \\
\text { Time to walk } \mathrm{T}_{\text {walk }}\end{array}$ & $296.7 \pm 34.2$ & $307.4 \pm 40.1$ & 0.150 \\
\hline
\end{tabular}

Values are mean \pm SD. Group L: levobupivacaine, Group B: bupivacaine. *One-way analysis of variance.

Table 4. Incidence of Adverse Events

\begin{tabular}{lccc}
\hline & Group L $(\mathrm{n}=50)$ & Group B $(\mathrm{n}=50)$ & P value $^{*}$ \\
\hline Hypotension & 6 & 16 & 0.028 \\
Bradycardia & 2 & 3 & 0.999 \\
Nausea & 7 & 9 & 0.780 \\
Vomiting & 2 & 4 & 0.677 \\
\hline
\end{tabular}

Values are number of patients. Group L: levobupivacaine, Group B: bupivacaine. *Fisher's exact test. 


\section{Discussion}

In the present study, intrathecal administration of $15 \mathrm{mg}$ isobaric levobupivacaine was compared with $15 \mathrm{mg}$ hyperbaric racemic bupivacaine in patients undergoing elective daycare unilateral inguinal hernia surgery. Levobupivacaine was as effective as bupivacaine in providing adequate quality of anesthesia. No difference was observed between the two with respect to the highest sensory level achieved. The duration of surgical anesthesia was shorter with levobupivacaine, as was the duration of motor blockade and the time required for ambulation. The incidence of intraoperative hypotension was lower with levobupivacaine.

Previous studies have shown levobupivacaine to be as effective as bupivacaine for use in subarachnoid block. Glaser et al. [11] compared $3.5 \mathrm{ml}$ of $0.5 \%$ isobaric levobupivacaine to $3.5 \mathrm{ml}$ of $0.5 \%$ racemic isobaric bupivacaine in 80 patients undergoing elective hip replacement. None of the 79 patients required supplemental analgesics during surgery. Cuvas et al. [12] compared $1 \mathrm{ml}$ of $0.5 \%$ plain bupivacaine to $0.5 \%$ levobupivacaine for a subarachnoid block in patients undergoing pilonidal sinus surgery performed in the prone position. All patients who received bupivacaine and $92 \%$ of the patients who received levobupivacaine were satisfied with the quality of anesthesia. Sahin et al. [9] compared $3 \mathrm{ml}$ of $0.5 \%$ isobaric bupivacaine to $3 \mathrm{ml}$ of $0.5 \%$ isobaric levobupivacaine in patients undergoing lumbar disc surgery and found no difference in patient satisfaction. On the other hand, Erdil et al. [7] compared $1.5 \mathrm{ml}$ of $0.5 \%$ levobupivacaine to $1.5 \mathrm{ml}$ of $0.5 \%$ plain bupivacaine in elderly patients undergoing transurethral prostate surgery and found greater patient satisfaction with the use of levobupivacaine. They attributed this to the lower incidence of hypotension and nausea with the use of levobupivacaine. In the present study, 44 of 50 patients in the levobupivacaine group and 46 of 50 patients in the bupivacaine group rated the quality of anesthesia as excellent. Five patients in group L and four patients in group B complained of ill-defined visceral sensations or uneasiness and required supplemental analgesia with intravenous fentanyl. One patient who received levobupivacaine complained of pain towards the end of the procedure and required conversion to general anesthesia. Overall, the quality of surgical anesthesia with levobupivacaine was adequate and comparable to that of bupivacaine.

The time to onset of sensory blockade was comparable between the two groups in our study. This finding is similar to those of previous studies [9,11-18]. As with previous studies $[11,13,17,19]$, we found no difference in the highest level of sensory block achieved. In contrast, Erdil et al. [7] observed a higher sensory level with bupivacaine. This may be due to the use of baricity bupivacaine, as opposed to hyperbaric bupivacaine in their study. Şahin et al. [9] reported a lower block height with the use of plain bupivacaine compared with levobupivacaine. Their study was performed in patients undergoing lumber disc surgery in the prone position. This change in patient position may have resulted in unequal spread of the two study drugs. As with previous studies, the onset of motor block onset was comparable in the two groups $[9,11,17]$.

In our study, the duration of surgical anesthesia was significantly shorter with levobupivacaine compared with bupivacaine (206.2 \pm 18.9 min vs. $224.1 \pm 15.6 \mathrm{~min}$ ). This finding is similar to the observations of Guler et al. [8] and Şahin et al. [9]. The faster offset of levobupivacaine may be due to the faster clearance of unbound levobupivacaine compared with dextrobupivacaine [20]. Notably, one patient in our study, who received levobupivacaine, complained of pain towards the end of the procedure and had to be converted to general anesthesia. It is likely that this represented faster waning of the sensory block with levobupivacaine than block failure.

Similarly, in our study, the duration of motor block was shorter with levobupivacaine than with bupivacaine. This finding corroborates those of Guler et al. [8] and Şahin et al. [9]. The faster offset of motor block resulted in quicker motor recovery, and time to walk unaided was significantly shorter with levobupivacaine than with bupivacaine $(321.9 \pm 21.2 \mathrm{~min}$ vs. $356.7 \pm$ $26.6 \mathrm{~min})$.

Studies comparing the duration of effective analgesia with levobupivacaine and bupivacaine have yielded conflicting results. Guler et al. [8] and Gautier et al. [21] reported that the duration of effective analgesia is shorter with levobupivacaine compared with bupivacaine. On the other hand, Hakan Erbay et al. [18] reported a longer duration of analgesia with levobupivacaine. Fattorni et al. [15] found no difference between the two. Our results showed no significant difference in the duration of effective analgesia between the groups. This wide variability in results may be attributed to the difference in the dose or baricity of the drugs used, and the nature of the surgery.

In our study, the incidence of hypotension was significantly less with the use of levobupivacaine than with bupivacaine (12\% vs. $32 \%$ ). This finding is similar to that of Erdil et al. [7] who found a $10 \%$ incidence of hypotension with levobupivacaine and $30 \%$ with bupivacaine. Bupivacaine, being a more potent local anesthetic than levobupivacaine [21], may cause greater sympathetic blockade, resulting in a greater incidence of hypotension.

In conclusion, $0.5 \%$ isobaric intrathecal levobupivacaine provided excellent quality of anesthesia in the majority of patients undergoing unilateral inguinal hernia surgery. Compared with hyperbaric racemic bupivacaine, it had a shorter duration of sensory and motor block, allowing earlier recovery and mobilization in daycare surgeries and a lower incidence of intraoperative hypotension. The shorter block recovery time may be a disadvantage for long procedures. However, this can be eliminated 
with proper patient selection. Hence, levobupivacaine can be a safer alternative to bupivacaine for infraumbilical surgeries of short duration.

\section{References}

1. Eledjam JJ, de la Coussaye JE, Bassoul B, Brugada J. Mechanisms of the cardiac toxicity of bupivacaine. Ann Fr Anesth Reanim 1988; 7: 20410 .

2. Chinachoti T, Tritrakarn T. Prospective study of hypotension and bradycardia during spinal anesthesia with bupivacaine: incidence and risk factors, part two. J Med Assoc Thai 2007; 90: 492-501.

3. Bardsley H, Gristwood R, Baker H, Watson N, Nimmo W. A comparison of the cardiovascular effects of levobupivacaine and racbupivacaine following intravenous administration to healthy volunteers. Br J Clin Pharmacol 1998; 46: 245-9.

4. Morrison SG, Dominguez JJ, Frascarolo P, Reiz S. A comparison of the electrocardiographic cardiotoxic effects of racemic bupivacaine, levobupivacaine, and ropivacaine in anesthetized swine. Anesth Analg 2000; 90: 1308-14.

5. Denson DD, Behbehani MM, Gregg RV. Enantiomer-specific effects of an intravenously administered arrhythmogenic dose of bupivacaine on neurons of the nucleus tractus solitarius and the cardiovascular system in the anesthetized rat. Reg Anesth 1992; 17: 311-6.

6. McLeod GA. Density of spinal anaesthetic solutions of bupivacaine, levobupivacaine, and ropivacaine with and without dextrose. Br J Anaesth 2004; 92: 547-51.

7. Erdil F, Bulut S, Demirbilek S, Gedik E, Gulhas N, Ersoy MO. The effects of intrathecal levobupivacaine and bupivacaine in the elderly. Anaesthesia 2009; 64: 942-6.

8. Guler G, Cakir G, Ulgey A, Ugur F, Bicer C, Gunes I, et al. A comparison of spinal anesthesia with levobupivacaine and hyperbaric bupivacaine for cesarean sections: A randomized trial. Open J Anesthesiol 2012; 2: 84-9.

9. Şahin AS, Türker G, Bekar A, Bilgin H, Korfalı G. A comparison of spinal anesthesia characteristics following intrathecal bupivacaine or levobupivacaine in lumbar disc surgery. Eur Spine J 2014; 23: 695-700.

10. Breen TW, Shapiro T, Glass B, Foster-Payne D, Oriol NE. Epidural anesthesia for labor in an ambulatory patient. Anesth Analg 1993; 77: 919-24.

11. Glaser C, Marhofer P, Zimpfer G, Heinz MT, Sitzwohl C, Kapral S, et al. Levobupivacaine versus racemic bupivacaine for spinal anesthesia. Anesth Analg 2002; 94: 194-8.

12. Cuvas O, Gulec H, Karaaslan M, Basar H. The use of low dose plain solutions of local anaesthetic agents for spinal anaesthesia in the prone position: bupivacaine compared with levobupivacaine. Anaesthesia 2009; 64: 14-8.

13. Casati A, Moizo E, Marchetti C, Vinciguerra F. A prospective, randomized, double-blind comparison of unilateral spinal anesthesia with hyperbaric bupivacaine, ropivacaine, or levobupivacaine for inguinal herniorrhaphy. Anesth Analg 2004; 99: 1387-92.

14. Cappelleri G, Aldegheri G, Danelli G, Marchetti C, Nuzzi M, Iannandrea G, et al. Spinal anesthesia with hyperbaric levobupivacaine and ropivacaine for outpatient knee arthroscopy: a prospective, randomized, double-blind study. Anesth Analg 2005; 101: 77-82.

15. Fattorini F, Ricci Z, Rocco A, Romano R, Pascarella MA, Pinto G. Levobupivacaine versus racemic bupivacaine for spinal anaesthesia in orthopaedic major surgery. Minerva Anestesiol 2006; 72: 637-44.

16. Mantouvalou M, Ralli S, Arnaoutoglou H, Tziris G, Papadopoulos G. Spinal anesthesia: comparison of plain ropivacaine, bupivacaine and levobupivacaine for lower abdominal surgery. Acta Anaesthesiol Belg 2008; 59: 65-71.

17. Luck JF, Fettes PD, Wildsmith JA. Spinal anaesthesia for elective surgery: a comparison of hyperbaric solutions of racemic bupivacaine, levobupivacaine, and ropivacaine. Br J Anaesth 2008; 101: 705-10

18. Hakan Erbay R, Ermumcu O, Hanci V, Atalay H. A comparison of spinal anesthesia with low-dose hyperbaric levobupivacaine and hyperbaric bupivacaine for transurethral surgery: a randomized controlled trial. Minerva Anestesiol 2010; 76: 992-1001.

19. Kokki M, Heikkinen M, Kumpulainen E, Vähäoja A, Kokki H. Levobupivacaine for spinal anesthesia in children: cerebrospinal fluid aspiration before the injection does not affect the spread or duration of the sensory block. Anesth Pain Med 2016; 6: e33815.

20. Burm AG, van der Meer AD, van Kleef JW, Zeijlmans PW, Groen K. Pharmacokinetics of the enantiomers of bupivacaine following intravenous administration of the racemate. Br J Clin Pharmacol 1994; 38: 125-9.

21. Gautier P, De Kock M, Huberty L, Demir T, Izydorczic M, Vanderick B. Comparison of the effects of intrathecal ropivacaine, levobupivacaine, and bupivacaine for Caesarean section. Br J Anaesth 2003; 91: 684-9. 